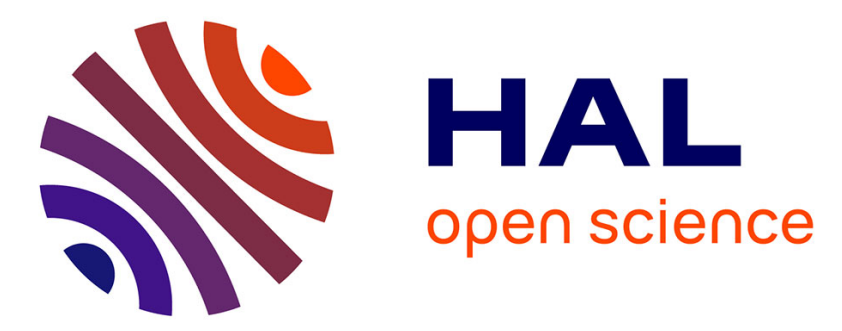

\title{
Mercury-free high pressure discharge lamps dominated by molecular radiation
}

\author{
M Käning, L Hitzschke, B Schalk, M Berger, St Franke, R Methling
}

\section{To cite this version:}

M Käning, L Hitzschke, B Schalk, M Berger, St Franke, et al.. Mercury-free high pressure discharge lamps dominated by molecular radiation. Journal of Physics D: Applied Physics, 2011, 44 (22), pp.224005. 10.1088/0022-3727/44/22/224005 . hal-00620591

\section{HAL Id: hal-00620591 \\ https://hal.science/hal-00620591}

Submitted on 8 Sep 2011

HAL is a multi-disciplinary open access archive for the deposit and dissemination of scientific research documents, whether they are published or not. The documents may come from teaching and research institutions in France or abroad, or from public or private research centers.
L'archive ouverte pluridisciplinaire HAL, est destinée au dépôt et à la diffusion de documents scientifiques de niveau recherche, publiés ou non, émanant des établissements d'enseignement et de recherche français ou étrangers, des laboratoires publics ou privés. 


\title{
Mercury-Free High Pressure Discharge Lamps Dominated by Molecular Radiation
}

\author{
M Käning ${ }^{1}$, L Hitzschke ${ }^{1}$, B Schalk ${ }^{2}$, M Berger ${ }^{1}$, St Franke ${ }^{3}$ \\ and R Methling ${ }^{3}$ \\ ${ }^{1}$ Research Europe, OSRAM GmbH, Werner-von-Siemens Straße 6, 86159 Augsburg, \\ Germany \\ ${ }^{2}$ Vitec Group Videocom Division, Erfurter Straße 16, 85386 Eching, Germany \\ ${ }^{3}$ INP, Leibniz-Institut für Plasmaforschung und Technologie e. V., \\ Felix-Hausdorff-Straße 2, 17489 Greifswald, Germany \\ E-mail: m.kaening@osram.de
}

\begin{abstract}
.
High intensity discharge (HID) lamps dominated by molecular radiation offer a very promising alternative for use in future light sources. They are able to deliver competitive efficacies of about $110 \mathrm{~lm} / \mathrm{W}$ and higher, excellent colour rendering index above 90 and a correlated colour temperature in the 3000-4000 K region at the operating point near the Planckian locus. Moreover these lamps are opening up the possibility of dimming. Due to the fact that they are able to omit mercury they are environmentally friendly.

The emission spectra generated by these HID lamps differ significantly from those of conventional lamps. The reason for this is the dominance of molecular radiation processes. In comparison to conventional HID lamps atomic contributions are usually rather small. In the present case they amount to less than about $10 \%$ of the total intensity in the visible range.
\end{abstract}

PACS numbers: 52.80.-s, 42.72.Bj, 52.70.Kz, 33.20.-t, 33.70.-w

Submitted to: J. Phys. D: Appl. Phys. 


\section{Introduction}

During the past decade the general understanding for sensitive, environmentally related issues has been sharpened substantially. One consequence of this is that lamp manufacturers have intensified their efforts not only to improve the energy efficiencies of light sources but also to eliminate hazardous substances in their products. For conventional high intensity discharge (HID) lamps the latter relates first of all to mercury and thallium. In principle it would seem that the avoidance of thallium is not difficult, but the same can not be said of mercury. The reason for this is that due to the high vapor pressure of mercury, and its large momentum transfer cross section for collisions with electrons, the operation voltage of HID lamps can be fixed at values of about $100 \mathrm{~V}$. The correspondingly moderate currents allow limiting the needs and inevitable efforts for the electronic control gear (ECG), the electrodes and last but not least also for lamp construction.

In addition to all of this and not less important is the fact that mercury has also a decisive impact on the resulting temperature profile of HID lamps [1-3]. The reason for this is that an energy redistribution due to UV radiation emitted from the hot arc core regions occurs and subsequently reabsorption processes at outer radial positions at lower plasma temperatures follow. As a result mercury influences not only the efficacy but also all other photometric data of the lamp. After consideration of these facts it becomes quite obvious that the elimination of mercury in HID lamps is anything but easy. The emphasis of the present contribution is on electroded systems for general lighting applications. Automotive lighting and electrode-less solutions are not the focus of this paper.

The straightforward strategy for mercury replacement is a direct substitution of mercury by a substance with similar high vapor pressure, corresponding momentum transfer cross-section as well as similar radiation properties [4-7].

A completely different concept of avoiding mercury in HID lamps is introduced in [8]. It started from the fact that, for a given power, the resulting discharge voltage is higher the smaller the arc cross section is. Furthermore, from earlier investigations it was known $[2,3,9]$ that molecular radiation emitted in the colder mantle region of the discharge is not only able to deliver the desired radiation in a quite efficient way, but also leads to the desired arc constriction. The explanation for the latter is as follows: due to the origin of the radiation in the mantle region this area is now cooling down. On the other hand, to allow a definite current to flow through the discharge, the core temperature has to be adequate. Therefore in case of rising power the core temperature is now increasing considerably. Based on this concept it is not only possible to remove mercury from HID discharges, but also to change their working principle substantially.

The present contribution starts exemplarily in section 2 with the characteristic shape of thulium mono-iodide emission. In section 3 it is shown that not only emission but also reabsorption due to thulium mono-iodide itself has to be taken into account to understand the radiation output of the discharge. The latter is backed by a direct 
measurement of this reabsorption. In section 4 the findings of [10] concerning the resulting photometric properties of thulium mono-iodide radiation are complemented with those of dysprosium mono-iodide. As a result of this a combination of both rareearth iodides is proposed since it provides improved properties as a light source. An example of a realization of an HID lamp dominated by molecular radiation is finally shown in section 5 .

\section{Molecular emission of thulium mono-iodide in HID with mercury}

This section briefly summarizes what is known about molecular radiation in conventional HID. In [9] for Hg-Ar-TlI-discharges with only one rare-earth component $\left(\mathrm{TmI}_{3}, \mathrm{HoI}_{3}\right.$, $\mathrm{DyI}_{3}$ ) the origin of quasi-continuous radiation was investigated in detail. For discharges burning in a typical $250 \mathrm{~W}$ quartz vessel at $P=240 \mathrm{~W}$ the radiation contribution of lines and the underlying continuum emitted from core and mantle regions of the arcs has been analyzed with a spectral resolution of $0.006 \mathrm{~nm}$. This way we were able to resolve lines from the continuum.

As a result it has been found that the vast number of atomic lines present in these spectra contribute roughly half of the total intensity emitted by the discharge whereas the other $50 \%$ has to be attributed to quasi-continuous molecular emission of mono-iodides. Further it was observed that the chemically more stable mercury monoiodide is responsible for radiation from the core, whereas the corresponding rare-earth mono-iodide was identified as emitting mainly in the mantle region. These finding are consistent with chemical composition calculations which reveal that mercury monoiodide $(\mathrm{HgI})$ is very stable, also at core temperature of about $6000 \mathrm{~K}$ whereas the maximum density of thulium mono-iodide (TmI) exists at medium radial positions at plasma temperatures between 3000 and $4000 \mathrm{~K}$. $\mathrm{TmI}_{3}$ is only stable at lower plasma temperatures close to the wall. Therefore temperature profiles with a plateau at medium radial positions and temperatures of about $3500 \mathrm{~K}$ support molecular radiation. Since the integral intensities of these two molecular contributions are comparable it followed that molecular rare-earth emission contributed actually about $25 \%$ to the total intensity. This amount of radiation contribution was considered to be unexpectedly high for this kind of discharge.

In a subsequent investigation, it turned out that the thulium mono-iodide emission could be assigned to two separate effective molecular excitation states. The data analysis revealed that the spectral distribution of the emission could be approximated by using two Gaussian line-shapes as a substitute for the very complex structure of the rotational vibrational electronic molecular transitions. Figure 1 depicts, for an example, the spectral distribution of the emission coefficient within the mantle region of the arc at a temperature of $3300 \mathrm{~K}$.

The applied procedure did not only allow the determination of effective excitation energies, but also an estimation of corresponding transition probabilities [9] for these molecular transition bands. However, it was found that the derived data depends very 


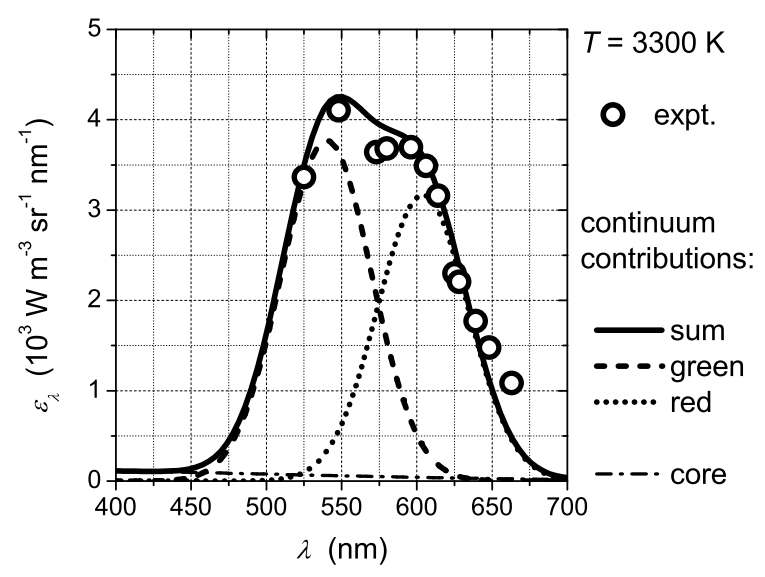

Figure 1. Emission coefficient of TmI radiation at $3300 \mathrm{~K}$ from [9]: circles are experimental data points, lines show the contributions according to the parametric approach approximating the TmI spectrum with two Gaussian profiles, a green and a red component depicted as dashed and dotted lines. Note, the contribution of the $\mathrm{HgI}$ core component (dashed-dotted line) is at this temperature still negligible.

sensitively on the quality of the temperature profile. Moreover, especially in the mantle region the latter is unaccessible for most common measurement techniques. Therefore an interpolation between measured arc core and wall temperatures has to be used. Furthermore it is also necessary to know the densities of TmI at the given temperatures. The TmI density can only be gained using thermochemical modeling which starts from the evaporated fill amount. An additional complication arises from radial demixing processes which have been taken into account.

The whole procedure of data processing and parameter determination for molecular continuum emission has not only been done for TmI, but also for HoI and DyI. However, corresponding parameters have been published only for TmI [9]. It should be noted that the data is to be used with caution keeping in mind all the limitations and complications described above.

To summarize, the most striking features of the investigated molecular radiation are that the broad ro-vibrational spectral structure delivers a significant contribution to plasma radiation and that the molecular emission can be effectively characterized as described above.

\section{Molecular radiation processes in $\mathbf{H g}$-free discharges}

\subsection{Molecular emission}

The investigations described in section 2 have been performed in quartz burners because the possibility of measuring the arc temperature profile by means of optical emission spectroscopy should not be sacrificed. This, however, limited the attainable wall temperatures to about $1000{ }^{\circ} \mathrm{C}[11]$.

In the attempt to further increase the evaporation of the rare-earth iodides the 
transition towards burners made of polycrystalline alumina (PCA) was necessary. Therefore standard cylindrical PCA burners for $P=150 \mathrm{~W}$ with a fill of $2 \mathrm{mg} \mathrm{AlI}_{3}$, $0.5 \mathrm{mg}$ TII, $4 \mathrm{mg} \mathrm{TmI}$ and 2 bar Xe as start gas were used to establish a discharge dominated by TmI molecular emission. For details on burner dimensions see burner type A1 in table 1 . The discharges were operated employing a current-amplifier which was driving a $50 \mathrm{~Hz}$ rectangular current waveform. For the lamps it was ensured that the additives $\mathrm{AlI}_{3}$ and TII were completely evaporated. Since $\mathrm{AlI}_{3}$ evaporates already at quite low temperatures it serves as a starting aid for the discharge, delivering enough burning voltage to allow for a fast power deposition into the arc during run-up. The purpose for TII as additive in commercial HID is to make use of the strong green Tl 535 $\mathrm{nm}$ line, which is located near the maximum of the spectral eye sensitivity. It effectively contributes to the discharge emission as well as allowing colour adjustment. This is why it was kept as a fill component also in these experiments.

Figure 2 shows irradiance spectra of the discharge for three different power levels. The spectral resolution of the Ocean Optics HR 2000 spectrometer used was $0.5 \mathrm{~nm}$. This allows for the measurement of the shape of the dominating molecular continuum, see also [9].

Note that the spectrum for $P=90 \mathrm{~W}$ in figure 2a resembles the spectral emission coefficient in figure 1. The typical thulium mono-iodide molecular quasi-continuum emission with some strong thulium atomic lines on top can clearly be seen. The main
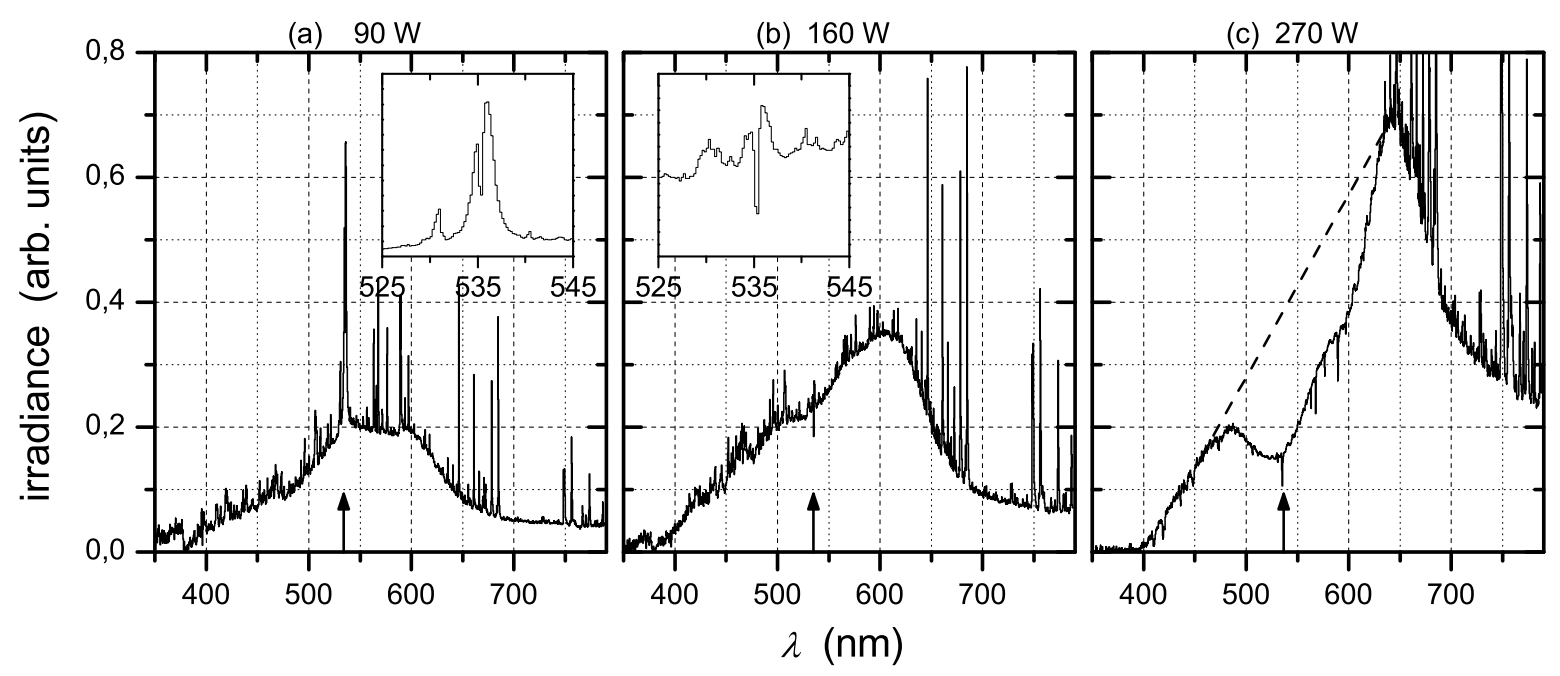

Figure 2. Irradiance spectra of a Xe-TII- $\mathrm{AlI}_{3}-\mathrm{TmI}_{3}$ discharge in a PCA burner for three different power levels measured with an optical fiber at a distance of about $15 \mathrm{~cm}$ from the arc.

Arrows mark the position of the prominent $\mathrm{Tl}$ line at $535 \mathrm{~nm}$, which is zoomed in insets for (a) and (b).

(a) $\mathrm{P}=90 \mathrm{~W}$ - continuum emission as known from discharges in quartz burners.

(b) $\mathrm{P}=160 \mathrm{~W}$ - beginning of molecular absorption.

(c) $\mathrm{P}=270 \mathrm{~W}$ - strong self-reversal for the whole molecular band between 460 and $640 \mathrm{~nm}$. For meaning of dashed line see discussion in the text. 
difference between both cases, however, is that figure 1 is characteristic only for the arc mantle region of the mercury containing discharge, whereas figure $2 \mathrm{a}$ is more like a spatially integrated spectrum of the complete mercury-free discharge lamp.

From figure 2a it is obvious that the TmI molecular radiation in the PCA burner now dominates the major part of the total emission. Actually a similar spectrum could also be obtained in quartz burners [11], but without further perspective to attain much higher power loads.

Note that in figure 2a the most prominent self-reversed $\mathrm{Tl}$ line at $535 \mathrm{~nm}$ is located on top of the continuum. This line is often used to determine the radial temperature profile of Tl-containing discharges via the Bartels method [12]. For the purpose of the following discussion it should be kept in mind that the intensity of this line's self-reversal shoulders is proportional to the maximum temperature met along the line-of-sight. The inset of figure $2 \mathrm{a}$ zooms the $\mathrm{Tl}$ line in order to show the absorption dip at the line center as well as the asymmetric line wings.

Starting from figure $2 \mathrm{a}$ the power was increased. The assumption was that in doing so not only the evaporation of $\mathrm{TmI}_{3}$ could be increased considerably, but also a corresponding increase of the emitted radiation would result. The latter part of this assumption turned out to be untrue as figure $2 \mathrm{~b}$ illustrates. First of all it is obvious that not only the general appearance of the original symmetric spectrum changed, but also that the $\mathrm{Tl} 535 \mathrm{~nm}$ line almost disappeared. The zoom in the inset of figure $2 \mathrm{~b}$ proves that although the $\mathrm{Tl}$ line is still visible it now shows quite a different line-shape than before. The intensity of the barely visible self-reversal shoulders on top of the TmI continuum has decreased in intensity by a factor of 10 which indicates that the whole line must have been absorbed. The alternative interpretation of the $\mathrm{Tl}$ line-shape change would mean that the core temperature must have dropped dramatically. However, since the power of the arc had been increased this interpretation is definitely unreasonable. Furthermore it is also obvious that all Tm atomic lines between 550 and $600 \mathrm{~nm}$ did not rise in intensity although all other lines above $600 \mathrm{~nm}$ did, the latter being a further proof for increasing core temperatures.

The physics behind these observations becomes evident if the power is increased even further. Figure 2c eventually shows a very different spectrum for a power of $P=$ $270 \mathrm{~W}$. Now there are absolutely no lines visible on top of the continuum between 350 and $640 \mathrm{~nm}$. The only indication of atomic transitions are absorption dips not only for Tl $535 \mathrm{~nm}$, but also for strong thulium atomic lines between 400 and $600 \mathrm{~nm}$. This means that all atomic radiation coming from the arc core gets absorbed and has no chance to escape the discharge.

The further comparison of figure $2 \mathrm{~b}$ and figure $2 \mathrm{c}$ shows that the general shaping of the irradiance spectra is indeed very similar for wavelengths below $460 \mathrm{~nm}$ and above $640 \mathrm{~nm}$. An exception, however, is the range between 460 and $640 \mathrm{~nm}$ where the spectral intensity actually further decreases. Again it is very likely that absorption is also responsible for this unexpected behaviour. To get some measure for this absorption, the dashed "base-line" is introduced in figure 2c. It connects the spectral irradiances at 
wavelengths 460 and $640 \mathrm{~nm}$ being the lower and upper margins towards similar spectral ranges.

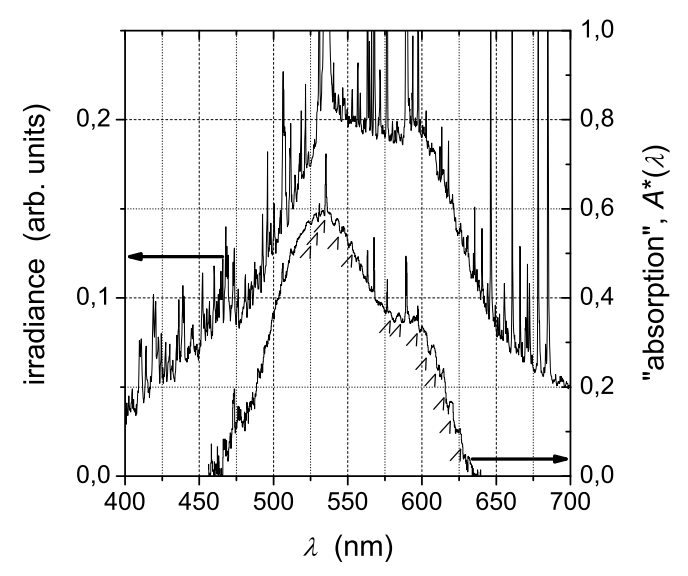

Figure 3. Left axis - top spectrum for $P=90 \mathrm{~W}$ (figure 2a).

Right axis - bottom absorption data for $\mathrm{P}=270 \mathrm{~W}$ computed from figure $2 \mathrm{c}$ (see text for discussion).

The intensity along the "base-line", $I_{B L}(\lambda)$, is used to estimate the "absorption", $A^{*}(\lambda)$, according to

$$
A^{*}(\lambda)=1-I(\lambda) / I_{B L}(\lambda) .
$$

The result for this "absorption" is plotted as the bottom trace in figure 3. Surprisingly the shaping of the absorption trace resembles the TmI spectrum at a low power. For comparison the emission spectrum for $P=90 \mathrm{~W}$ from figure $2 \mathrm{a}$ is included as the upper trace in figure 3 . Check also the similarity of the absorption trace to figure 1.

As discussed in [9], quasi continuum emission of mono-halides consists of many merged electronic rotational vibrational bands which can barely be seen in radiation spectra in the case of TmI. In the absorption trace, however, molecular bands do show up as tiny humps (marked with little hooks in figure 3 ). This is clear additional evidence of molecular structures. In the following section the "absorption", $A^{*}(\lambda)$, will therefore be referred to as molecular self-absorption.

\subsection{Molecular absorption}

The facts and discussion above already strongly indicate the importance of molecular dominated processes in Hg-free lamps. Nevertheless, to conclude the discussion a final independent proof for the existence of molecular absorption processes in these lamps has been carried out. The experimental setup for this experiment is given in figure 4 .

A spherical mirror was placed at the doubled focal length behind the lamp. Hence, the light emitted by the lamp was reflected and focused back to the arc along the 


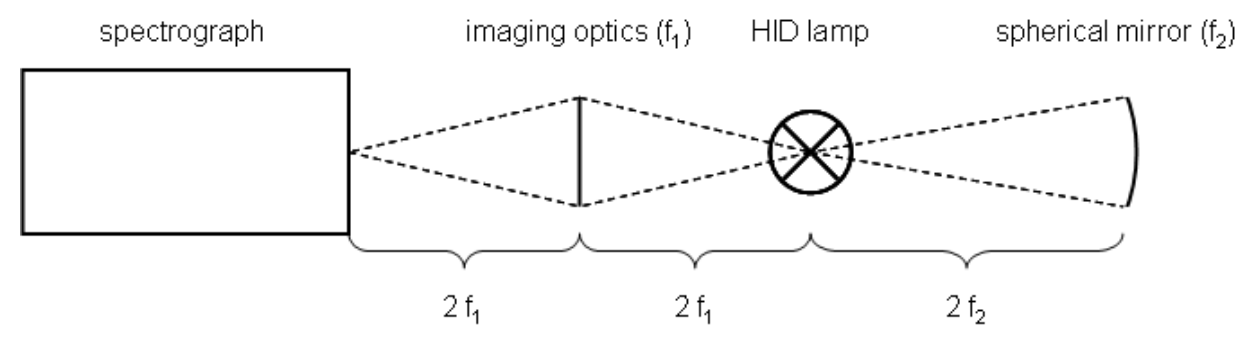

Figure 4. Experimental setup for absorption measurements $\left(f_{1}=500 \mathrm{~mm}, f_{2}=\right.$ $200 \mathrm{~mm})$.

optical axis. By means of an 1:1 imaging optics the arc is projected onto the entrance slit of a spectrograph in Czerny-Turner-con guration with $0.75 \mathrm{~m}$ focal length (Solar TII MS7504) and $20 \mu \mathrm{m}$ entrance slit. Spectral radiances were recorded by a CCD line camera (Proscan HLS191HD, 1024 pixel) with a spectral resolution of $0.03 \mathrm{~nm}$ (FWHM).

The lamp under investigation consisted of a quartz vessel with a quartz enclosure. Its inner diameters were about 8 and $19 \mathrm{~mm}$ with $1.5 \mathrm{~mm}$ thicknesses of quartz tubes. The electrode distance was about $18 \mathrm{~mm}$. The lamp was filled with Xe at 1 bar as well as with $2 \mathrm{mg} \mathrm{AlI} 3,1.1 \mathrm{mg} \mathrm{TmI}$ and $0.5 \mathrm{mg}$ TII and operated with $120 \mathrm{~Hz}$ square wave at a nominal power of $150 \mathrm{~W}$.

In the optically thin limit, spectral radiances should be doubled with the spherical mirror behind the lamp. However, one had to take into account the reflection losses at quartz surfaces of the lamp. Hence, the ratio of radiances is given by

$$
\frac{L_{1}(\lambda)}{L_{0}(\lambda)}=1+T_{\text {quartz }}^{k} \times R_{\text {mirror }} \times(1-A(\lambda)) .
$$

Here $L_{1}(\lambda)$ and $L_{0}(\lambda)$ represent the spectral radiances measured with and without the mirror, respectively. The plasma absorption is given by $A(\lambda)$. The quartz surface transmission coefficient is obtained from Fresnel formulas to be $T_{\text {quartz }}=0.965$ assuming a refraction index of 1.46. The exponent $k$ considers the increased number of quartzambient-surfaces that the reflected light has to pass $(k=8$ due to burner and outer bulb walls). With a reflectivity of the spherical mirror of $R_{\text {mirror }}=0.99$ the maximum spectral radiance that could be observed in the optically thin limit is about factor 1.74 of that measured without the mirror. The absorption technique used works reliably only in the radial centre of the arc tube.

In figure 5a the spectral radiance of the lamp from 450 to $700 \mathrm{~nm}$ is given. It has been measured in the middle between the electrodes in the discharge axis. Both humps of the TmI emission can clearly be seen. (Compare also with figure 2.) The figure 5b represents the spectral absorption of the plasma, $A(\lambda)$, as obtained from the absorption measurement described just above. Maximum absorption is observed in the line centre of the self-reversed Tl $535 \mathrm{~nm}$ line. However, absorption of TmI molecules already reaches values between 0.4 and 0.6 . 


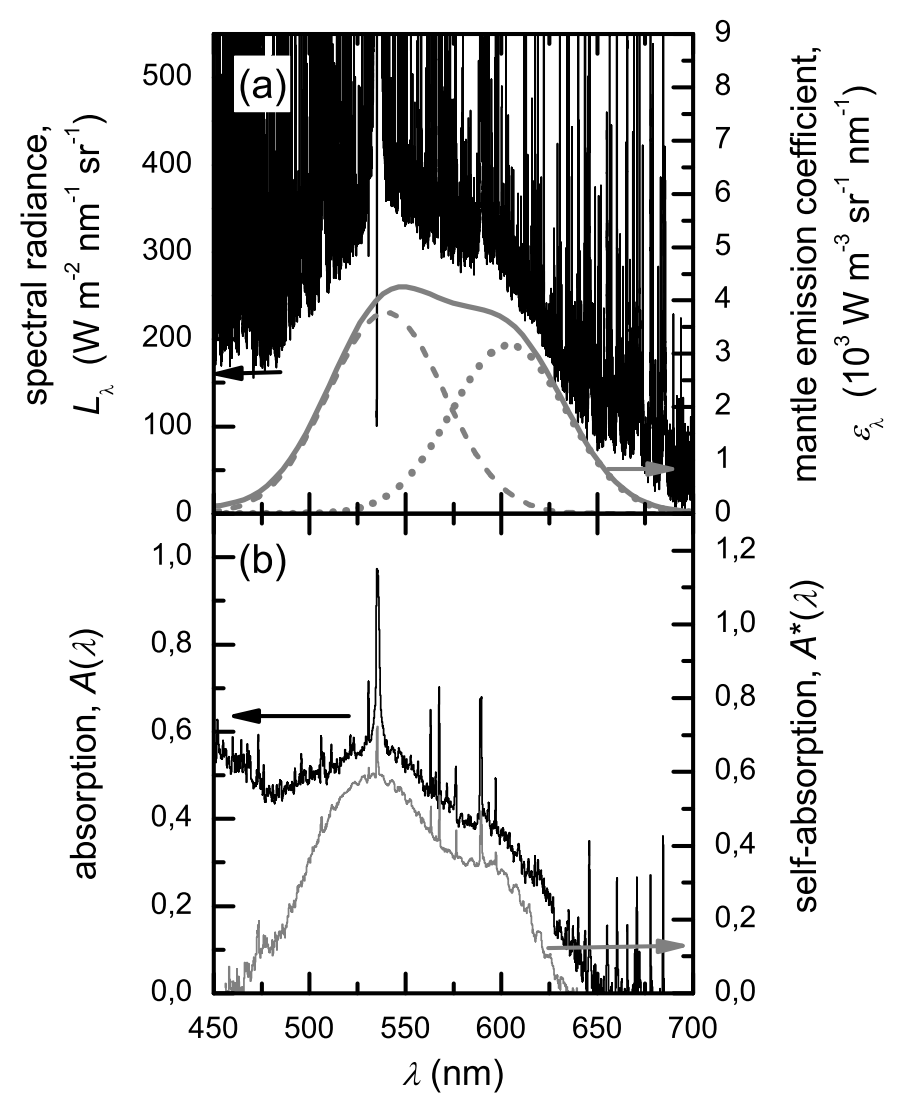

Figure 5. (a) Spectral radiance of Hg-free lamp in the middle between the electrodes in the discharge axis (left axis). Emission coefficient of TmI radiation obtained from the mantle region of a $\mathrm{Hg}$-containing lamp taken from figure 1 (right axis).

(b) Absorption, $A(\lambda)$, of $\mathrm{Hg}$-free lamp as obtained from absorption measurements (left axis). Self-absorption, $A^{*}(\lambda)$, as obtained from self-reversed molecular emission of Hg-free lamp with ceramic vessel in figure 3 (right axis).

Qualitatively the measured absorption profile can be compared with the selfabsorption, $A^{*}(\lambda)$, derived in figure 3 . Therefore it has been included in figure $5 \mathrm{~b}$. The comparison of both absorption shapes reveals the following: In the wavelength range between 530 and $640 \mathrm{~nm}$ the coincidence of both traces is rather striking, however, they deviate in the blue spectral region.

The deviation in the blue can be explained by considering obviously existing absorption processes also in this wavelength area. Besides the absorption already discussed in the green and red region, it has to be mentioned that there are additional absorption processes in the blue spectral range. It is known that the $\mathrm{Tl} 378 \mathrm{~nm}$ line as well as TII on the red wing of the Tl $378 \mathrm{~nm}$ line do in fact cause strong absorption 
in the blue spectral region up to $520 \mathrm{~nm}$ [9]. As figure 2 shows, the increase of power results in a complete disappearance of the spectral emission below $400 \mathrm{~nm}$. This has also partly to be attributed to TmI itself. A more detailed discussion of this for other rare-earth iodides is also given in [13].

The existence of additional absorption in the blue spectral range means that the base-line in figure $2 \mathrm{c}$ has to start at a higher irradiance at $460 \mathrm{~nm}$. In doing so the resulting absorption values of $A^{*}(\lambda)$ below $530 \mathrm{~nm}$ would increase sufficiently and become similar to the ones measured for $A(\lambda)$. In addition it has to be kept in mind that two different discharge lamps are being compared.

\subsection{Summary on molecular emission and molecular absorption}

To conclude the discussion of this section, it can be stated that the shaping of the spectra of molecular dominated discharges is the result of the interplay of molecular emission and molecular reabsorption. In particular, the very distinct absorption feature observed in figure $2 \mathrm{c}$ is in fact a self-reversal of the whole molecular transition band. It is in complete analogy with absorption dips of self-reversed atomic transitions in inhomogeneous optically thick plasmas - for example in case of the Tl $535 \mathrm{~nm}$ line - and has never been reported before.

Hg-free HID lamps investigated in this paper exhibit several unique properties, compared to conventional HID solutions:

- The spectrum is dominated by molecular radiation.

- The molecular plasma is usually optically thick within large wavelength areas.

- The molecular spectrum can be self-reversed.

- The molecular radiation itself causes plasma conditions to enforce molecular radiation. By radiative cooling constricted temperature profiles are formed with a plateau at medium radial positons, where rare-earth mono-iodides are stable and their densities are highest, so that these molecules can effectively radiate.

- The electric field strength is increased by a constriction of the plasma temperature profile, whereby the arc core temperature is increased and the diameter of the conductive channel is significantly reduced.

\section{Photometric data of Hg-free HID dominated by molecular emission}

In [10] a detailed analysis of a discharge with $\mathrm{TmI}_{3}$ as additive has been given with focus on the photometric data. It could be shown that a discharge relying on thulium mono-iodide as the only molecular radiator already reaches very promising photometric properties.

As known a $\Delta C$ value for a given spectrum defines the distance of its chromaticity coordinates from the Planckian locus and in this way it is able to reflect the general colour impression of the emission. For light sources which should meet the requirements 
for general lighting applications the corresponding absolute $\Delta C$ values have to be very small, to allow for the impression of a really white emitting light source without colour fault. Unfortunately, the weak point of using only $\mathrm{TmI}$ is this $\Delta C$ behaviour. In fact the $\Delta C$ values for $\mathrm{TmI}_{3}$-based discharges vary rather strongly with power, compare figure 7a. This implies that a lamp using TmI as the only molecular radiator will respond to small power changes rather sensitively. Power shifts would not only effect the temperature profile inside the arc, but also the evaporation of the salts due to a change of wall temperature. This in turn directly influences the density and the corresponding emission of the molecular radiators.

In order to check the corresponding $\Delta C$ behaviour of other rare-earth mono-iodides additional investigations have been conducted [13].

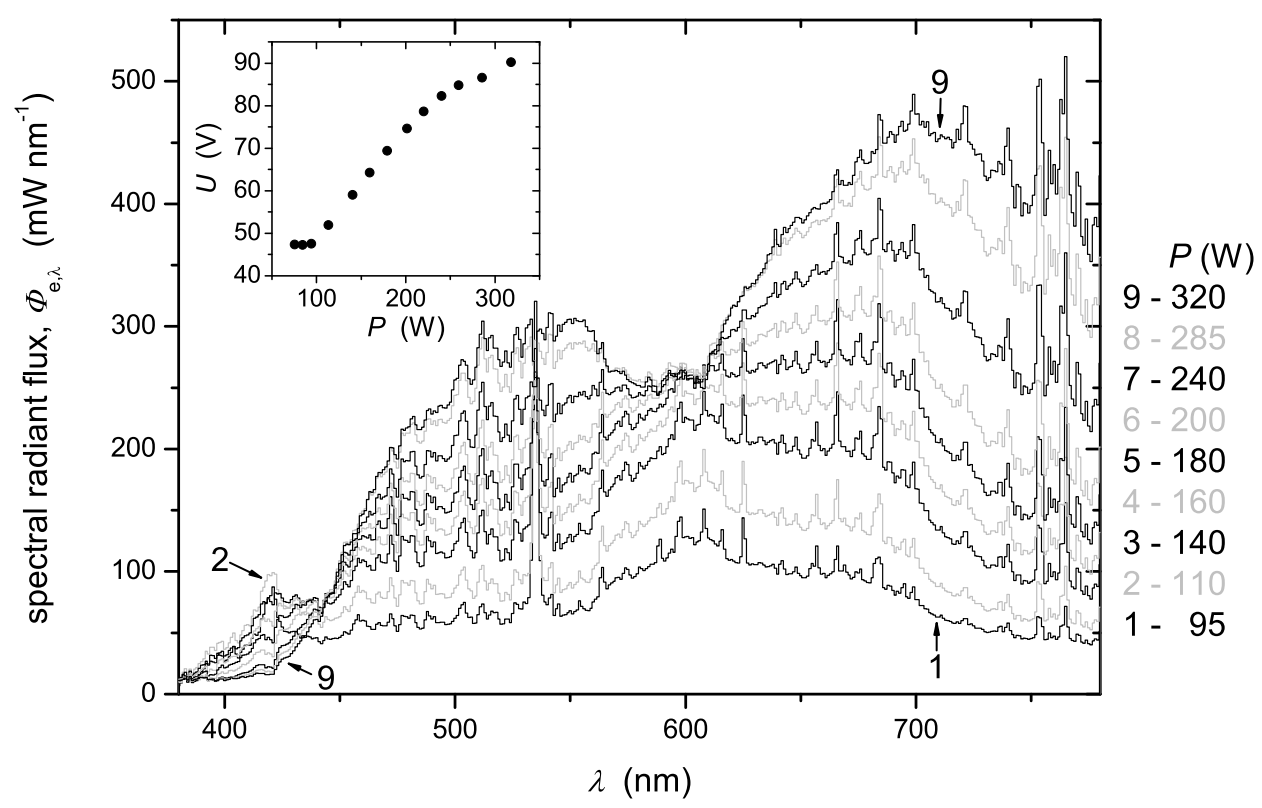

Figure 6. Spectral radiant flux of a discharge with $\mathrm{DyI}_{3}$ as additive (discharge type A2 in table 1) measured in an integrating sphere for different power levels between 95 and $320 \mathrm{~W}$. The inset shows the corresponding burning voltage, $U(P)$.

Figure 6 shows spectra for a discharge with $\mathrm{DyI}_{3}$ as additive (refer to discharge type A2 in table 1), measured in an integrating sphere. As in case of TmI one can see for a low power the two typical maxima of dysprosium mono-iodide (DyI) molecular quasi-continuum emission located at approximately 600 and $670 \mathrm{~nm}$. Besides these two bands there is also a broad-band quasi-continous molecular contribution in the whole VIS range starting already below $400 \mathrm{~nm}$.

With increasing power the emission bands grow in intensity until the emission band centered at about $600 \mathrm{~nm}$ shows clear signs of self-reversal. As a consequence, the 
intensities at $\lambda=600 \mathrm{~nm}$ observed in spectra measured above a power of $200 \mathrm{~W}$ appear to be pinned at $260 \mathrm{~mW} \mathrm{~nm}^{-1}$. The absorption feature between 560 and $630 \mathrm{~nm}$ becomes more visible the higher the discharge power. The onset of molecular self-reversal of the $670 \mathrm{~nm}$ band emission can only be guessed for the highest power levels above $280 \mathrm{~W}$. As in the case of TmI the plasma seems to be optically thin above the $670 \mathrm{~nm}$ DyI band.

In comparison to TmI, for DyI more light can escape the plasma in the range between 480 and $560 \mathrm{~nm}$, since the $600 \mathrm{~nm}$ DyI band does not yet heavily affect this range. The $\mathrm{Tl} 535 \mathrm{~nm}$ line, however, is clearly being absorbed. Especially above $200 \mathrm{~W}$ the line is not even observed in emission anymore.

A second point of pinned intensity is visible at $447 \mathrm{~nm}$ for spectra above $150 \mathrm{~W}$ below which increasing self-absorption can be seen. This blue absorption is steeper and stronger than in case of TmI.
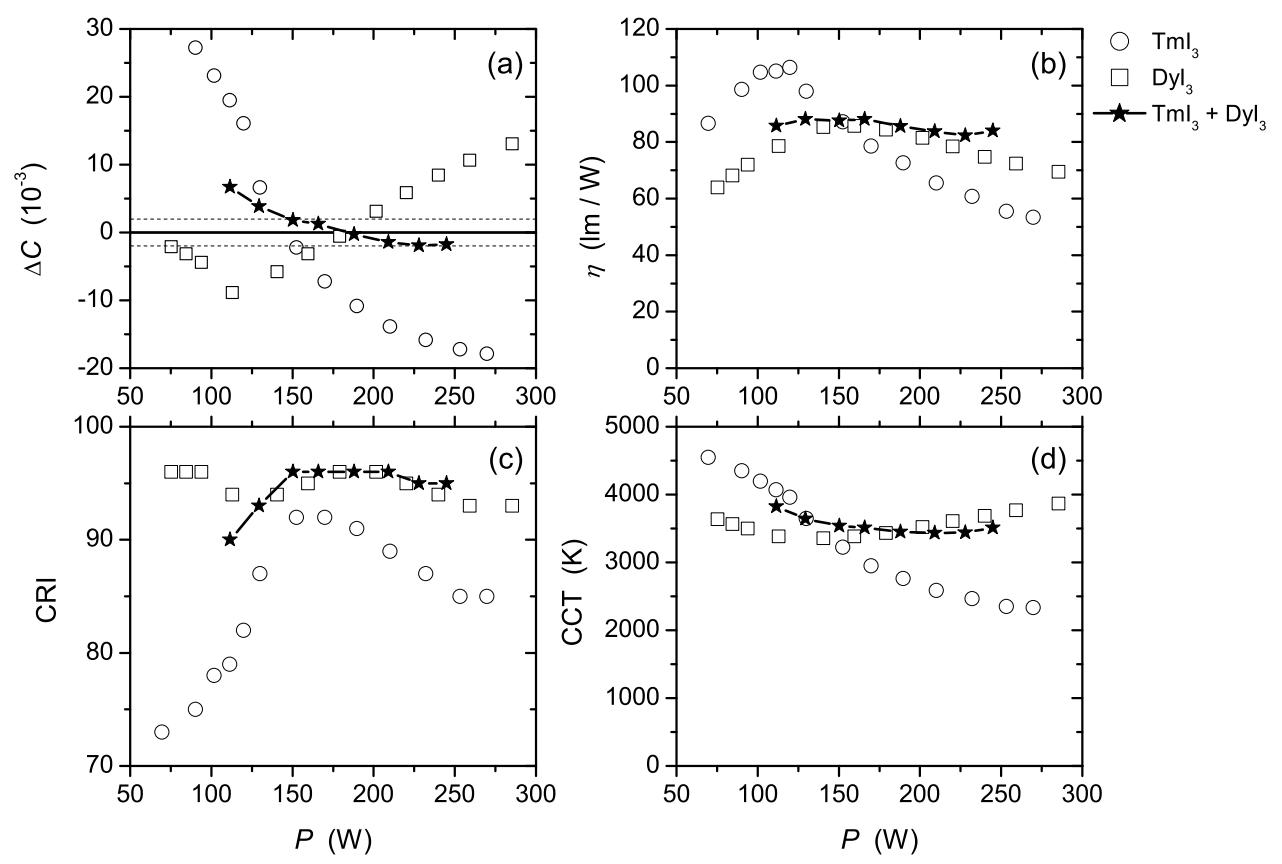

Figure 7. Photometric data for discharges having only either $\mathrm{TmI}_{3}, \mathrm{DyI}_{3}$ and a mixture of both added (discharge types A1, A2, and A3 in table 1) with (a) deviation from the Planckian locus, (b) efficacy, (c) colour rendering index and (d) correlated colour temperature. (Values calculated from spectra like those shown in figures 6 and 8.)

Inspection of photometric data gained from spectra in figure 6 reveals that in contrast to other rare-earths DyI has a $\Delta C$ dependence with opposite slope to TmI during power variation (see figure 7a). As for TmI this effect is caused by the interplay between molecular emission and molecular self-absorption of DyI molecules. 
The opposite $\Delta C$ slopes of $\mathrm{TmI}$ and DyI raise the question whether a combination of both molecular radiators could lead to a discharge with a flatter $\Delta C$ dependence with power change. Therefore lamps have been investigated containing a 1:1 mixture of $\mathrm{TmI}_{3}$ and $\mathrm{DyI}_{3}$ (refer to discharge type A3 in table 1). Figure 7a demonstrates that the mixture does indeed meet the above expectations and therefore can contribute to much better colour stability and dimming properties.

Furthermore, in addition to a flat $\Delta C$ behaviour the colour rendering index is of high interest. Figure $7 \mathrm{c}$ proves that the $\mathrm{TmI}_{3}+\mathrm{DyI}_{3}$ discharge can actually maintain the excellent colour rendering index (CRI) around 95 of a purely $\mathrm{DyI}_{3}$-based discharge. Consequently figure 7d shows less correlated colour temperature (CCT) changes with power variation. Moreover, figure $7 \mathrm{~b}$ makes it obvious that the discharge containing the rare-earth mixture allows to keep high efficacies between 85 and $90 \mathrm{~lm} / \mathrm{W}$ over a wider power range even better than $\mathrm{DyI}_{3}$ alone and does not show the strong efficacy drop observed for discharges based on $\mathrm{TmI}_{3}$ only.
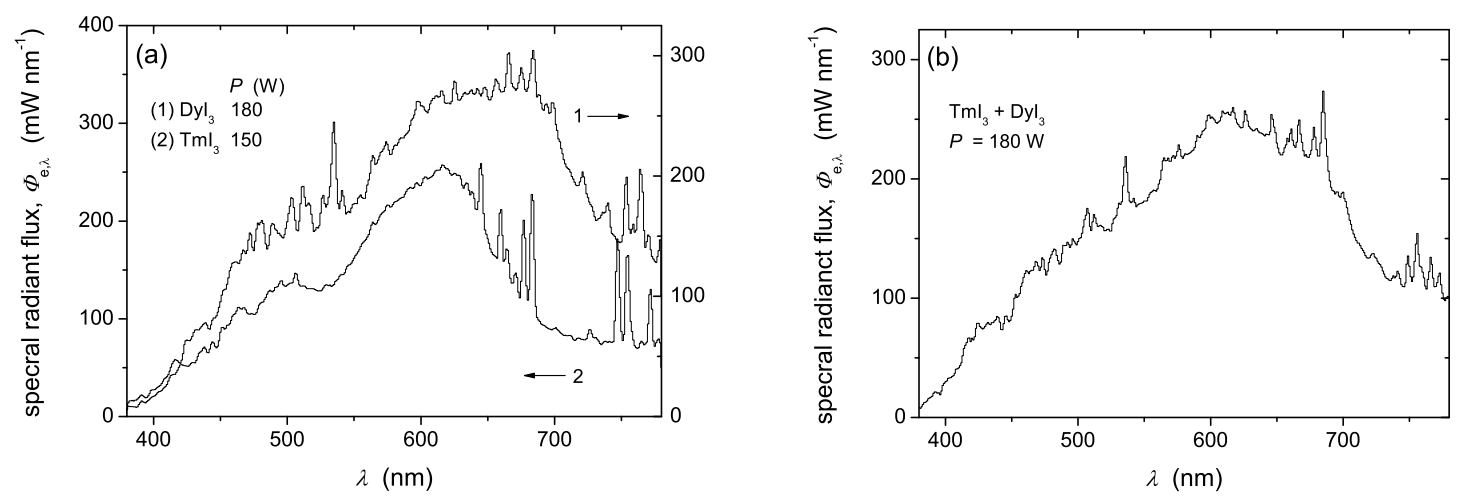

Figure 8. Spatially integrated spectra measured in an integrating sphere shown for the corresponding power, $P$, for which the deviation from the Planckian locus is smallest $\left(|\Delta C|<2 \cdot 10^{-3}\right)$.

(a) Only $\mathrm{DyI}_{3}$ (1) or $\mathrm{TmI}_{3}$ (2) as additive. Mind the slightly differing intensity axes for the two spectra assigned by arrows next to data trace number.

(b) A 1:1 mixture of $\mathrm{DyI}_{3}$ and $\mathrm{TmI}_{3}$ as additive.

To give an impression of the resulting spectra at operating point figure 8 exemplarily shows spectra for discharges with $\mathrm{TmI}_{3}, \mathrm{DyI}_{3}$ and the mixture of both as additive. The operation point is thereby defined by the power where the spectrum has an absolute $\Delta C$ value close to zero. See also table 2 for comparison of electric and photometric data at this operating point.

Figure 8a displays clearly the emission and absorption characteristics of TmI discussed above for $P=150 \mathrm{~W}$. In addition the characteristic shape of the red dysprosium mono-iodide molecular emission being responsible for the high CRI values achieved is visible between 550 and $720 \mathrm{~nm}$ at $P=180 \mathrm{~W}[9]$. 
The merging together of these molecular spectra in case of the rare-earth mixture is demonstrated in figure $8 \mathrm{~b}$ for $P=180 \mathrm{~W}$. While this spectrum very much resembles that of DyI, the influence of TmI is seen in the strong absorption of the $535 \mathrm{~nm} \mathrm{Tl}$ line caused by the $548 \mathrm{~nm}$ TmI molecular band [9].
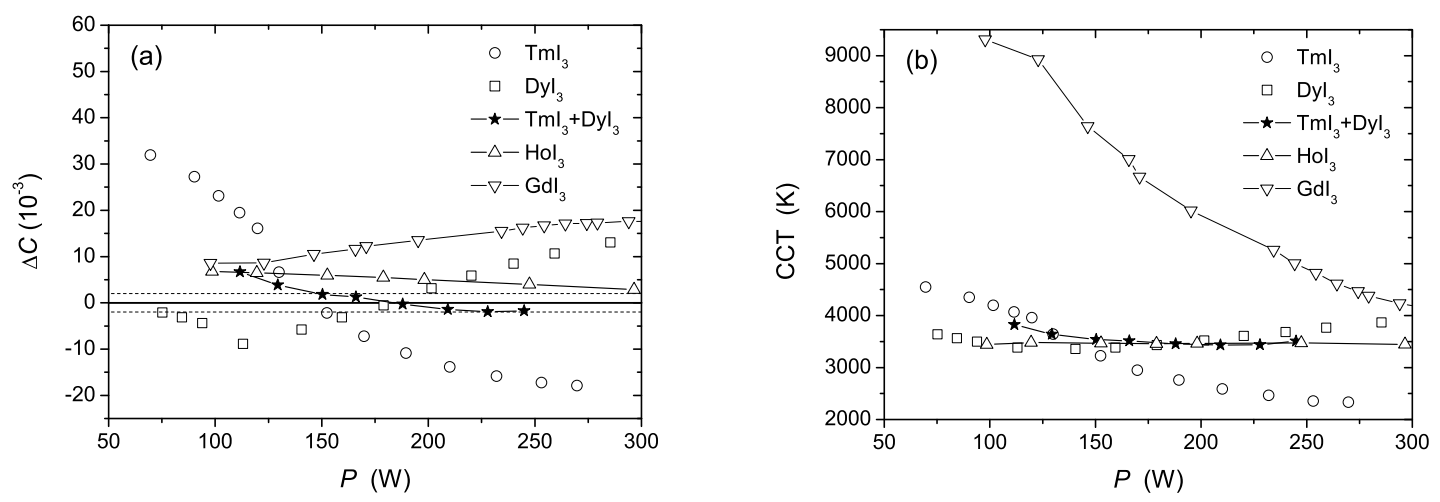

Figure 9. Specific photometric data versus power, $P$, for various rare-earth additives. (a) Deviation from the Planckian locus, $\Delta C$ and (b) correlated colour temperature, CCT.

The above results raise the question of whether other rare-earths iodides might be viable candidates for molecular radiation dominated HID lamps. Exemplarily $\mathrm{HoI}_{3}$ and $\mathrm{GdI}_{3}$ shall be discussed here, whereas more information can be found in [13]. $\mathrm{HoI}_{3}$ has been taken as a suitable fill component because it was known that the shape of the HoI spectrum is similar to those of TmI and DyI, but its center is located in between theirs [9]. Due to opposite $\Delta C$ - and CCT-slopes for TmI and DyI a rather neutral behaviour of HoI could be expected. The expectation was found to be true, as can been seen in figures 9a,b. Over the whole power range HoI's change of the deviation from the Planckian locus as well as the CCT variation is very small compared to what had been measured for TmI and DyI. However, for HoI $\Delta C$ is systematically above the Planckian locus and therefore HoI is taken on its own not an alternative to the other two molecular radiators, although it could be an interesting additive. This actually explains why usually commercial rare-earth-based fills rely on the $\mathrm{Tm}+\mathrm{Ho}+\mathrm{Dy}$ triplet.

As a counterexample the rare-earth iodide $\mathrm{GdI}_{3}$ shall be presented in figure 9 . Although the GdI emission has also a smaller $\Delta C$ variation than TmI the correlated colour temperature, however, is varying far too much. The latter is the reason why GdI is not favored to be used for general lighting applications.

\section{From Hg-free HID dominated by molecular emission towards a lamp}

Besides the results described above there are still additional opportunities for improvements of Hg-free HID lamps based on molecular emission. Possible pathways 
are:

- burner geometry adaption for optimization of emission/absorption processes,

- fill composition optimization,

- electronic operation mode adaption,

- application of unsaturated HID lamps, e.g. using the technological breakthrough described in [14].

This work is following the more traditional approaches beginning with a suitable burner design. All discharges presented up to now were operated in cylindrical PCA vessels with a fairly small aspect ratio of $L / D=13 \mathrm{~mm} / 9 \mathrm{~mm} \approx 1.4$ (discharge types A1, A2, and A3 in table 1). In order to increase the efficacy and the operational stability of the lamp, the reduction of the quite large inner diameter had to be especially considered as a very favourable measure, because

(i) a higher temperature of the coldest spot enhances rare-earth iodide evaporation,

(ii) a longer arc reduces the influence of electrode losses,

(iii) a higher aspect ratio eases the acoustic stabilization of the constricted arc,

(iv) and additional absorption losses decrease in a reduced cold boundary layer. This additional absorption can be caused by $\mathrm{I}_{2}$ molecules in the blue/green or rare-earth mono-iodides in the blue spectral region as pointed out also in section 3.2.

The cylindrical burner shape with its flat ends had been found to be disadvantageous with respect to longitudinal or longitudinally mixed acoustic resoncances. Therefore a slimmer burner with non-flat end-shapes has been selected.

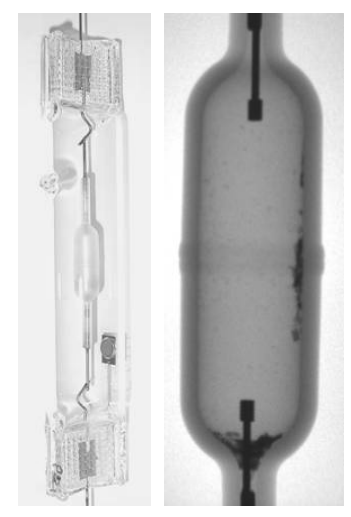

Figure 10. Hg-free lamp with outer envelope (left) and a X-ray (right) of the burner with spherical end-shapes.

Figure 10 examplarily shows an example of a more suitable burner with an aspect ratio of $L / D=19 / 5 \mathrm{~mm} \approx 4$ and an electrode gap of $14 \mathrm{~mm}$ (discharge type $\mathrm{B}$ in table 1 ). The end-shapes have now become spherical to ensure a better damping of longitudinal acoustic resonances. 
It has been discussed above that molecular emission causes substantial arc constriction. This constriction leads to a loss of wall stabilization. To compensate this an electronically supported acoustic stabilization is required to ensure safe operation of such arcs. This is why lamps of this type can not be operated on a conventional ballast, but need a special ECG which has been developed. With the new type of ECG it was possible to achieve a stable operation of the lamps at voltages of $70-100 \mathrm{~V}$, compare also [10].

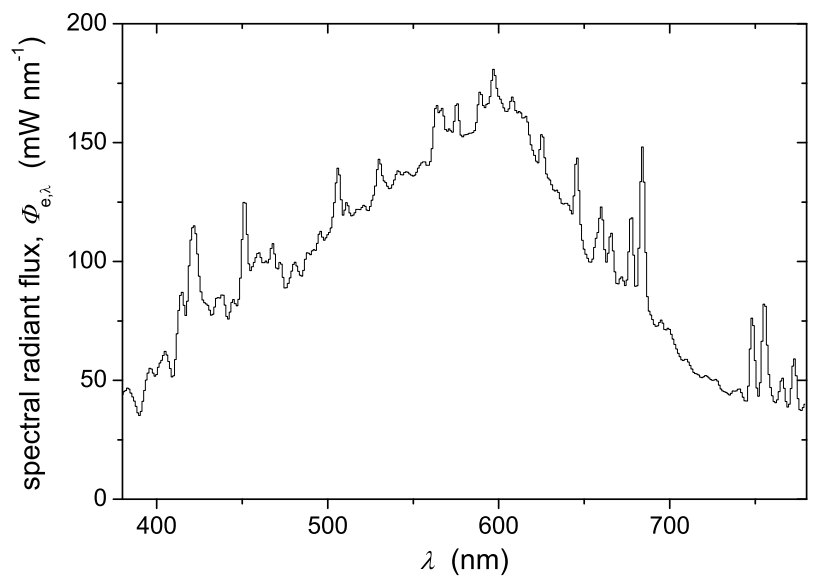

Figure 11. Spectrum of an optimized Hg-free HID lamp (discharge type B of table 1) for $P=95 \mathrm{~W}$ resulting in an efficacy of $108 \mathrm{~lm} / \mathrm{W}$, CRI about $91,|\Delta C|<2 \cdot 10^{-3}$, CCT about $4220 \mathrm{~K}$.

In the next step the fill composition has been adapted to the new design. In the previous section it was demonstrated that a fill consisting of equal amounts of $\mathrm{TmI}_{3}$ and $\mathrm{DyI}_{3}$ resulted in an improved spectrum. For the improved burner it was found that a $\mathrm{TmI}_{3}: \mathrm{DyI}_{3}$ mass ratio of $7: 3$ is most favourable regarding the photometric data at high efficacy. Furthermore, to avoid absorption losses in the blue spectral range, thallium iodide has been omitted as a fill component. Instead indium mono-iodide has been introduced, mainly as a getter for free iodine, but also to push the blue emission. The resulting spectrum of this new burner is shown in figure 11. For the sake of comparison, the important photometric parameters obtained are appended to table 2 were the ones of investigations based on cylindrical burners discussed in sections 3.1 and 4 are shown. As can be seen for the new lamp design an efficacy of $108 \mathrm{~lm} / \mathrm{W}$ with a CRI of 91 and CCT of $4220 \mathrm{~K}$ has been achieved.

Indeed, the results of this section present only a little step forward towards an optimized lamp. Investigations show that a further reduction of the inner diameter would be even more favorable.

The fill system itself plays a very important role for further improved lamp properties. Up to now, in the light of the proposed molecular emission concept only 
Table 1. Geometric data of PCA burners and rare-earth fill additives used for investigations of various discharge types presented in this paper.

Burner dimensions: $L$ - inner length, $D$ - inner diameter, $d$ - electrode gap.

All burners use 2 bar xenon as start gas.

\begin{tabular}{|c|c|c|c|c|c|c|}
\hline \multirow{2}{*}{$\begin{array}{l}\text { discharge } \\
\text { type }\end{array}$} & \multicolumn{4}{|c|}{ burner geometry } & \multicolumn{2}{|c|}{ rare-earth additive } \\
\hline & end-shape & $\begin{array}{c}L \\
(\mathrm{~mm})\end{array}$ & $\begin{array}{c}D \\
(\mathrm{~mm})\end{array}$ & $\begin{array}{c}d \\
(\mathrm{~mm})\end{array}$ & components & $\begin{array}{l}\text { mass } \\
(\mathrm{mg})\end{array}$ \\
\hline A1 & & & & & $\mathrm{TmI}_{3}$ & 4 \\
\hline $\mathrm{A} 2$ & flat & 13 & 9.1 & 10 & $\mathrm{DyI}_{3}$ & 4 \\
\hline A3 & & & & & $\mathrm{TmI}_{3}+\mathrm{DyI}_{3}(1: 1)$ & 4 \\
\hline B & spherical & 19 & 5 & 14 & $\mathrm{TmI}_{3}+\mathrm{DyI}_{3}(7: 3)$ & 6 \\
\hline
\end{tabular}

Table 2. Electric and photometric data at operating point, $P_{\mathrm{O}}$ (where $|\Delta C|$ of spectrum is close to zero), for HID lamps of different burner geometries and fill compositions.

Power range between $P_{l}$ and $P_{u}$ with acceptably small deviation from Planckian locus $\left(|\Delta C|<2 \cdot 10^{-3}\right)$.

\begin{tabular}{|c|c|c|c|c|c|c|c|c|}
\hline \multirow{2}{*}{$\begin{array}{l}\text { discharge } \\
\text { type }\end{array}$} & \multirow{2}{*}{ fill system } & \multicolumn{2}{|c|}{ electric } & \multicolumn{3}{|c|}{ photometric data } & \multicolumn{2}{|c|}{ power range } \\
\hline & & $\begin{array}{l}P_{\mathrm{O}} \\
(\mathrm{W})\end{array}$ & $\begin{array}{c}U_{\mathrm{O}} \\
(\mathrm{V})\end{array}$ & $\begin{array}{c}\eta \\
(\mathrm{lm} / \mathrm{W})\end{array}$ & CRI & $\begin{array}{c}\mathrm{CCT} \\
(\mathrm{K})\end{array}$ & $\begin{array}{c}P_{l} \\
(\mathrm{~W})\end{array}$ & $\begin{array}{c}P_{u} \\
(\mathrm{~W})\end{array}$ \\
\hline A1 & $\mathrm{TmI}_{3}$ & 145 & 69 & 90 & 90 & 3420 & 140 & 150 \\
\hline $\mathrm{A} 2$ & $\mathrm{DyI}_{3}$ & 180 & 70 & 84 & 96 & 3435 & 170 & 195 \\
\hline A3 & $\mathrm{TmI}_{3}+\mathrm{DyI}_{3}(1: 1)$ & 180 & 61 & 87 & 96 & 3455 & 150 & 250 \\
\hline B & $\mathrm{TmI}_{3}+\mathrm{DyI}_{3}(7: 3)$ & 95 & 95 & 108 & 91 & 4220 & 70 & 110 \\
\hline
\end{tabular}

very few components have been investigated. The inclusion of further components in conjunction with discharge vessel and electronic operation optimizations opens a whole new world of possibilities.

\section{Summary}

High intensity discharge lamps dominated by molecular radiation do in fact offer a very promising alternative for use in future light sources. They are able to deliver competitive efficacies of about $110 \mathrm{~lm} / \mathrm{W}$ and higher, excellent CRI above 90 and a CCT in the 3000$4000 \mathrm{~K}$ region at the operating point near the Planckian locus. Moreover these lamps are opening up the possibility of dimming. Due to the fact that they are able to omit mercury they are environmentally friendly.

The emission spectra generated by these HID lamps differ significantly from those of conventional lamps. The reason for this is the dominance of molecular radiation processes. In comparison to conventional HID lamps atomic contributions are usually 
rather small. In the present case they amount to less than about $10 \%$ of the total intensity in the visible range.

\section{Acknowledgments}

The authors want to thank the German BMBF for government funding (projects 13N7411, 13N7413, 13N8261 and 13N8262), OSRAM's research lamp building department and last but not least colleagues at the INP Greifswald (especially H. Hess, H. Schneidenbach, H. Schöpp and G. Hartel) for years-long cooperation.

\section{References}

[1] G. Hartel, H. Schöpp, H. Hess, and L. Hitzschke. Radiation from an alternating current highpressure mercury discharge: A comparison between experiments and model calculations. $J$. Appl. Phys., 85(10):7076-7088, 1999.

[2] B. Schalk. Funktionsprinzip des Entladungsplasmas quecksilberhaltiger Metallhalogenidlampen. $\mathrm{PhD}$ thesis, TU München, 2007.

[3] B. Schalk, G. Hartel, M. Käning, and L. Hitzschke. Influence of power balance and radiation transport on temperature distributions of HID discharges. In Proc. 11th Int. Symp. Sci. and Technol. of Light Sources, page 323, 2007.

[4] M. Born. Untersuchungen zum Ersatz des Quecksilbers in keramischen Hochdruckgasentladungen mit Hilfe von metallischem Zink. ISBN: 3-89653-788-1, 2000.

[5] M. Born. Mercury free high pressure discharge lamps. In Proc. 9th Int. Symp. Sci. and Technol. of Light Sources, page 43, 2001.

[6] M. Born, H. Giese, and I. Niemann. Abschlußbericht BMBF-Projekt 13N8264, 2005.

[7] M. Ohnesorge. Untersuchungen zur Hochtemperaturchemie quecksilberfreier MetallhalogenidEntladungslampen mit keramischem Brenner. PhD thesis, TH Aachen, 2005.

[8] L. Hitzschke, G. Hartel, A. Kloss, K. Stockwald, B. Schalk, and M. Käning. Abschlußbericht BMBF-Projekt 13N8261, 2005.

[9] M. Käning, B. Schalk, and H. Schneidenbach. Experimental determination of parameters for molecular continuum radiation of rare-earth iodides. J. Phys. D: Appl. Phys., 40(13):3815$3822,2007$.

[10] M. Käning, L. Hitzschke, B. Schalk, M. Berger, St. Franke, and R. Methling. Mercury-free HID lamps. In Proc. 12th Int. Symp. Sci. and Technol. of Light Sources and the 3rd Int. Conf. White LEDs and Solid State Lighting, pages 477-484, Eindhoven, The Netherlands, 2010.

[11] St. Franke, R. Methling, H. Hess, H. Schneidenbach, H. Schöpp, L. Hitzschke, M. Käning, and B. Schalk. Mercury-free high-intensity discharge with high luminous efficacy and good colour rendering index. J. Phys. D: Appl. Phys., 40(13):3836-3841, 2007.

[12] H. Schneidenbach and St Franke. Basic concepts of temperature determination from self-reversed spectral lines. J. Phys. D: Appl. Phys., 41(14):144016, 2008.

[13] R. Methling, St. Franke, L. Hitzschke, M. Käning, and B. Schalk. Molecular Radiation from overcharged Hg-free HID. In Proc. 12th Int. Symp. Sci. and Technol. of Light Sources and the 3rd Int. Conf. White LEDs and Solid State Lighting, pages 471-472, Eindhoven, The Netherlands, 2010.

[14] J. Hendricx, J. Vrugt, C. Denissen, and J. L. G. Suijker. Unsaturated ceramic metal-halide Lamps, A new generation of HID lamps. In Proc. 12th Int. Symp. Sci. and Technol. of Light Sources and the 3rd Int. Conf. White LEDs and Solid State Lighting, pages 405-414, Eindhoven, The Netherlands, 2010. 